\title{
Therapeutic effect of radiofrequency ablation on children with supraventricular tachycardia and the risk factors for postoperative recurrence
}

\author{
CHUNLI LI, LIBO JIA, ZHENZHOU WANG, LING NIU and XINJIANG AN \\ Department of Cardiovascular Medicine, The Affiliated Children's Hospital of \\ Xuzhou Medical University, Xuzhou, Jiangsu 221006, P.R. China
}

Received October 3, 2017; Accepted February 27, 2018

DOI: $10.3892 /$ etm.2018.5986

\begin{abstract}
The present study investigated the therapeutic effect of radiofrequency ablation on children with supraventricular tachycardia (SVT), and explored the risk factors for postoperative recurrence. A total of 312 patients with pediatric SVT were selected in the Affiliated Children's Hospital of Xuzhou Medical University from April, 2011 to March, 2017. All the patients were subjected to radiofrequency ablation, and clinical data were retrospectively analyzed. Tilt table test was performed before and after treatment, and heart rate, systolic and diastolic blood pressure before and after treatment were compared. Plasma levels of D-dimer (D-D), platelet $\alpha$-granule membrane protein (GMP-140) and thrombin-antithrombin III complex (TAT) were detected by enzyme-linked immunosorbent assay before treatment, immediately after radiofrequency oblation, and at 1, 3 and 7 days after treatment. Treatment outcomes were compared between the atrioventricular reentrant tachycardia (AVRT) and atrioventricular nodal reentrant tachycardia (AVNRT) groups. Risk factors for postoperative recurrence were analyzed. Supine position heart rate after treatment was not significantly different from that before treatment $(\mathrm{P}>0.05)$, while the upright position heart rate was significantly increased after treatment $(\mathrm{P}<0.05)$. Systolic pressures of the supine and upright positions were significantly reduced after treatment compared with the levels before $(\mathrm{P}<0.05)$, but no significant differences were found in diastolic blood pressure of supine and the upright position $(\mathrm{P}>0.05)$. No significant difference in radiofrequency ablation rate, recurrence rate and incidence of complications
\end{abstract}

Correspondence to: Dr Xinjiang An, Department of Cardiovascular Medicine, The Affiliated Children's Hospital of Xuzhou Medical University, 18 Sudibei Road, Xuzhou, Jiangsu 221006, P.R. China

E-mail: anxinjian001@163.com

Key words: radiofrequency ablation, supraventricular tachycardia, postoperative recurrence, residual slow pathway, inaccurate targeting were found between the AVRT and AVNRT groups $(\mathrm{P}>0.05)$. After radiofrequency, the levels of D-D, GMP-140 and TAT ablation showed an upward trend, but decreased at day 7 to reach preoperative levels. Logistic regression analysis revealed that residual slow pathway $(\mathrm{OR}=6.718, \mathrm{P}=0.005)$ and inaccurate targeting $(\mathrm{OR}=2.815, \mathrm{P}=0.007)$ were independent risk factors for postoperative recurrence $(\mathrm{P}<0.05)$. Although radiofrequency ablation can damage the cardiac vagal nerve, resulting in an increase in the heart rate after ablation during the course of the tilt table test and changed hemagglutination state within one week after ablation, those changes returned to normal after one week. The efficacy of radiofrequency ablation in the treatment of pediatric SVT is clear, and recurrence rate is low. Residual slow pathway and inaccurate targeting were independent risk factors for postoperative recurrence.

\section{Introduction}

Supraventricular tachycardia (SVT) is one of the most common types of arrhythmias in clinical practice, especially in children (1). SVT mainly develops from the regions above ventricles, and the increased heart rate is usually not accompanied with organic changes in heart tissue, and RR interval and QRS wave detected by ECG were usually normal (2). The pathogenesis of VST includes atrioventricular reentrant tachycardia (AVRT) and atrioventricular nodal reentrant tachycardia (AVNRT). SVT can cause chest tightness, palpitations embolism and severe tachycardia ventricular fibrillation, or even life-threatening complications (3).

As a safe and effective intervention strategy, radiofrequency ablation has been proven to be effective in the treatment of arrhythmia (4). With the improvement of the quality of catheter materials, radiofrequency ablation is becoming more and more mature, and has been gradually applied to the radical treatment of SVT (5). However, recurrence after radiofrequency ablation, can cause physical and mental pain, and increase medical expenses, and constitutes a great challenge for the application of this technique (6).

In the present study, the outcomes of radiofrequency ablation in the treatment of children with SVT were evaluated, and risk factors for postoperative recurrence were analyzed to provide references for the reduction of recurrence. 


\section{Materials and methods}

General information. A total of 312 patients with pediatric SVT were selected from April, 2011 to March, 2017. The clinical data of the patients were retrospectively analyzed. The patients were subjected to radiofrequency ablation, and no organic heart disease was observed. Family members of the patients signed informed consent. The study was approved by the Ethics Committee of the Affiliated Children's Hospital of Xuzhou Medical University (Xuzhou, China). General information of the patients is listed in Table I.

Preoperative preparation. Preoperative routine examinations, including chest X-ray, electrocardiogram, echocardiography, coagulation examination and other tests were performed for the patients. Treatment with antiarrhythmic drugs was stopped at 5 half-life before the study, and treatment with anticoagulant drugs was stopped 3 days before surgery. The patients were not allowed to eat or drink for $6 \mathrm{~h}$ prior to surgery. The puncture sites were cleaned, and antibiotics were used to prevent infection 30 min prior to surgery. Tilt table test was performed in a room with soft lights. Heart rate, blood pressure and other parameters were recorded.

Radiofrequency ablation. For AVNRT mapping and radiofrequency ablation, anesthesia was performed by sevoflurane inhalation. ECG and the back electrode plate were connected. After conventional disinfection, the right internal jugular and the right femoral vein were punctured to place the sheath, and the catheter was sent to the right atrium. Discharge $(25 \mathrm{w})$ was performed for 5-10 sec on the position of $1 / 3$ below the connection live of hex beam electrode and coronary sinus electrode. The appearance of junctional and sinus rhythm indicated an effective discharge. The discharge was extended approximately to $3 \mathrm{~min}$. If the ablation was not successful, discharge was performed on another target. Heart rate was monitored during ablation, and intravenous injection of dexamethasone was administered in case of atrioventricular block. Discharge was stopped when heart rate returned to normal.

AVRT mapping and radiofrequency ablation: After conventional disinfection, the right femoral vein and internal jugular vein were punctured to place the sheath, and ablation catheter was sent to the left ventricle or right atrium to hook on the tricuspid annulus. Small A large V wave was mapped to serve as an ablation target, and discharge (25 v) was performed for $10 \mathrm{sec}$. VA separation and disappearance of bypass or reverse transmission function indicated an effective discharge. Discharge was extended to $3 \mathrm{~min}$, and heart rhythm was monitored, and appropriate treatment was performed.

Evaluation indicators. Tilt table test was performed on the first day before and the second day after radiofrequency ablation. Heart rate, systolic and diastolic blood pressure in children were observed. Plasma levels of D-dimer (D-D), platelet $\alpha$-granule membrane protein (GMP-140) and thrombin-antithrombin III complex (TAT) were detected by enzyme-linked immunosorbent assay using kits provided by Shanghai Sun Biotech Co., Ltd. (Shanghai, China). The success rate of radiofrequency ablation and recurrence rate of SVT were measured by intracardiac electrophysiology,
Table I. General information of the patients.

Items

Patients $n=312$

Male $\mathrm{n}(\%)$

166 (53.21)

Female n (\%)

146 (46.79)

Age (years)

3-13

Average age (years)

$8.36 \pm 2.47$

Average weight $(\mathrm{kg})$

$33.54 \pm 3.73$

AVRT n (\%)

158 (50.64)

AVNRT n (\%)

$154(49.36)$

AVRT, atrioventricular reentrant tachycardiagroup; AVNRT, atrioventricular nodal reentrant tachycardia group.

Table II. Changes in heart rate before and after ablation (bpm).

\begin{tabular}{lcccc}
\hline Variables & Before & After & t-value & P-value \\
\hline $\begin{array}{l}\text { Supine } \\
\text { position }\end{array}$ & $71.29 \pm 7.43$ & $71.84 \pm 7.04$ & 0.949 & 0.343 \\
$\begin{array}{l}\text { Upright } \\
\text { position }\end{array}$ & $80.83 \pm 7.34$ & $86.78 \pm 7.35$ & 10.118 & $<0.001$ \\
5 min & $82.98 \pm 7.15$ & $87.43 \pm 7.48$ & 7.596 & $<0.001$ \\
10 min & $83.09 \pm 7.27$ & $87.67 \pm 7.26$ & 7.874 & $<0.001$ \\
15 min & $81.24 \pm 7.46$ & $86.87 \pm 7.38$ & 9.477 & $<0.001$ \\
\hline
\end{tabular}

and the incidence of surgical related complications including severe hematoma, severe pleural effusion, hemothorax and atrioventricular block were recorded.

Statistical analysis. SPSS 19.0 (SPSS Inc., Chicago, IL, USA) software was used. Measurement data were expressed as mean \pm standard deviation (false), and comparisons between pre- and post-operative levels within a group were performed using ANOVA and the post hoc test was Dunnett's test. Countable data were expressed as rate, and processed using $\chi^{2}$ test. Comparisons among multiple data within a group were performed by repeated measurements of variance analysis. Influencing factors were performed by Logistic regression analysis. $\mathrm{P}<0.05$ was considered to indicate a statistically significant difference.

\section{Results}

Comparison of heart rate of supine and upright position before and after treatment. After treatment, the heart rate of the supine position was not significantly different from that before treatment $(\mathrm{P}>0.05)$, while the heart rate of the upright position was significantly increased after treatment $(\mathrm{P}<0.05)$ (Table II).

Comparison of systolic blood pressure of supine and upright position before and after treatment. Compared with preoperative levels, systolic blood pressure of supine and upright position were significantly reduced (Table III). 
Table III. Comparison of systolic blood pressure before and after treatment.

\begin{tabular}{lcccc}
\hline Variables & Before & After & t-value & P-value \\
\hline $\begin{array}{l}\text { Supine } \\
\text { position }\end{array}$ & $128.26 \pm 8.43$ & $121.85 \pm 8.04$ & 9.719 & $<0.001$ \\
$\begin{array}{l}\text { Upright } \\
\text { position }\end{array}$ & $117.85 \pm 6.36$ & $110.72 \pm 6.37$ & 13.991 & $<0.001$ \\
5 min & $116.98 \pm 6.15$ & $110.23 \pm 6.05$ & 13.820 & $<0.001$ \\
10 min & $118.46 \pm 6.23$ & $112.62 \pm 6.19$ & 11.746 & $<0.001$ \\
15 min & $120.56 \pm 6.45$ & $115.27 \pm 6.38$ & 10.299 & $<0.001$ \\
\hline
\end{tabular}

Table IV. Comparison of diastolic blood pressure before and after treatment.

\begin{tabular}{lcccc}
\hline Variables & Before & After & t-value & P-value \\
\hline $\begin{array}{l}\text { Supine } \\
\text { position }\end{array}$ & $77.23 \pm 5.43$ & $76.87 \pm 5.54$ & 0.820 & 0.413 \\
$\begin{array}{l}\text { Upright } \\
\text { position }\end{array}$ & $75.87 \pm 5.32$ & $75.78 \pm 5.36$ & 0.211 & 0.833 \\
5 min & $75.68 \pm 5.19$ & $75.43 \pm 5.28$ & 0.596 & 0.551 \\
10 min & $76.59 \pm 5.24$ & $76.67 \pm 5.36$ & 0.189 & 0.850 \\
15 min & $77.36 \pm 5.48$ & $77.87 \pm 5.52$ & 1.158 & 0.247 \\
\hline
\end{tabular}

Table V. Comparison of efficacy and recurrence rate between AVRT and AVNRT group, n (\%).

\begin{tabular}{lcccc}
\hline Groups & Cases & $\begin{array}{c}\text { Immediate } \\
\text { success rate }\end{array}$ & $\begin{array}{c}\text { Recurrence } \\
\text { rate }\end{array}$ & $\begin{array}{c}\text { Incidence } \\
\text { of complications }\end{array}$ \\
\hline AVRT & 158 & $155(98.10)$ & $7(4.43)$ & $0(0.00)$ \\
AVNRT & 154 & $150(97.40)$ & $8(5.19)$ & $1(0.65)$ \\
$\chi^{2}$ & & 0.001 & 0.003 & 0.001 \\
P-value & & 0.927 & 0.959 & 0.990 \\
\hline
\end{tabular}

AVRT, atrioventricular reentrant tachycardiagroup; AVNRT, atrioventricular nodal reentrant tachycardia group.

Comparison of diastolic blood pressure of supine and upright position before and after treatment. Compared with preoperative levels, no significant changes in diastolic blood pressure of supine and upright position were found after treatment (Table IV).

Comparison of efficacy and recurrence rate. No significant differences in immediate success rate, recurrence rate and the incidence of complications were found between the AVRT and AVNRT groups $(\mathrm{P}>0.05)$ (Table V).

Comparison of coagulation function before and after radiofrequency ablation. Plasma levels of D-D, GMP-140 and TAT significantly increased at 1 and 3 days after ablation compared with preoperative levels. The levels of those factors were decreased on day 7 to reach normal level (Fig. 1).

Analysis of risk factors for postoperative recurrence. With postoperative recurrence as a dependent variable, sex, ablation time, radio frequency current power, residual slow path and inaccurate targeting were used as independent variables. Residual slow path $(\mathrm{OR}=6.718, \mathrm{P}=0.005)$ and inaccurate targeting $(\mathrm{OR}=2.815, \mathrm{P}=0.007)$ were proved to be independent risk factors for the recurrence (Table VI).

\section{Discussion}

SVR is mostly caused by the reentry mechanism. Reentrance usually occurs in atrioventricular node, atrium, sinus node and atrioventricular junction and other parts. As a cause of rapid arrhythmia, AVRT is caused by the presence of reentry ring between bypass and normal conduction pathway, and accounts for approximately $60 \%$ of SVT. AVNRT is the formation of AVNRT caused by the presence of double atrioventricular junction, and AVNRT accounts for approximately $30 \%$ of SVT (7-9).

SVT is usually treated with drugs, such as digitalis and propafenone injection, and DC shock, but the recurrence rate is high (10). As a minimally invasive treatment, radiofrequency ablation has been applied to the treatment of SVT since 1990s. With the high safety, SVT now has become a first-line treatment for SVT (11). The principle of radiofrequency ablation is to heat myocardial tissue through the radio frequency, so as to destroy focal myocardium (12). In the present study, no significant differences in immediate success rate, recurrence rate and the incidence of complications were found between AVRT and AVNRT groups $(\mathrm{P}>0.05)$. This is because radiofrequency ablation can map the causes of arrhythmia (abnormal reentry and ectopic discharge) through electrode, and the release of high-frequency current to the target was performed through ablation catheter to heat the target tissue $\left(43\right.$ to $60^{\circ} \mathrm{C}$ ), so as to denature proteins in myocardial tissues to cause coagulation necrosis, thus reducing electrical conduction and achieve the purpose of treatment (13). With the advantages of no radioactive damage, easy operation and high safety, radiofrequency ablation will not cause air pressure injury and damages to surrounding normal myocardial tissue. In addition, the incidence of postoperative complications and postoperative recurrence rate of this method are also relatively low (14).

The results of the present study showed that there was no significant difference in heart rate of the supine position before and after radiofrequency ablation $(\mathrm{P}>0.05)$, while heart rate of the upright position was significantly increased after treatment $(\mathrm{P}<0.05)$. After treatment, systolic pressures of both supine and upright position were significantly reduced compared with the levels before treatment $(\mathrm{P}<0.05)$, while no significant changes in diastolic blood pressure of supine and the upright position were found ( $\mathrm{P}>0.05)$. This is because radiofrequency ablation can easily cause damage to autonomic nerves close to the endocardium. The autonomic nerves, especially vagus nerve is close to the myocardial wall and is more sensitive to radiofrequency ablation, and heart rate usually increases during treatment, and decline in peripheral vascular resistance 
Table VI. Logistic regression analysis of factors affecting recurrence after ablation.

\begin{tabular}{lcccccc}
\hline Factors & $\beta$ & SE & Wald & OR & 95\%CI & P-value \\
\hline Sex & 0.718 & 0.374 & 2.421 & 0.312 & $0.106-0.854$ & 0.105 \\
Ablation time & 0.605 & 0.504 & 4.427 & 0.706 & $0.496-0.842$ & 0.216 \\
Residual slow path & 0.567 & 0.636 & 7.703 & 6.718 & $2.075-9.212$ & 0.005 \\
Inaccurate targeting & 0.637 & 0.518 & 5.568 & 2.815 & $1.103-4.046$ & 0.007 \\
Radio frequency current power & 0.156 & 0.442 & 2.713 & 0.783 & $0.275-0.912$ & 0.356 \\
\hline
\end{tabular}
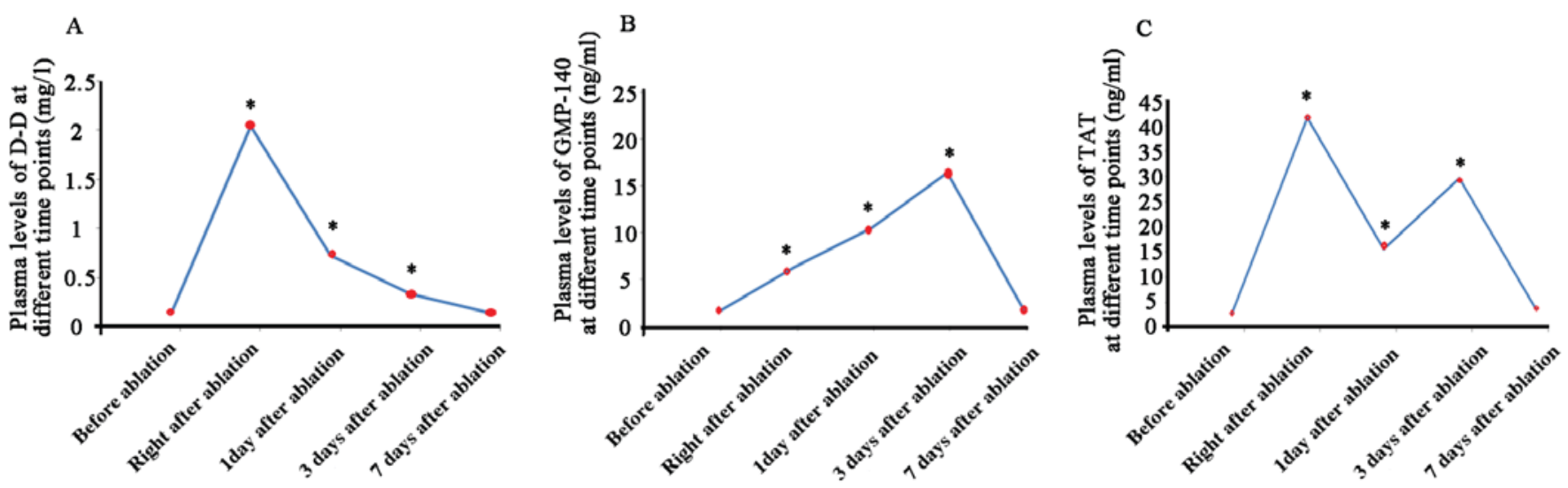

Figure 1. Plasma levels of: (A), D-D; (B), GMP-140; and (C) TAT, at different time points. "Compared with preoperative levels, P<0.05

and systolic blood pressure can also occur. By contrast, the area of ablation is limited, and the impact on blood pressure is not serious (15).

Although radiofrequency ablation is a minimally invasive surgery, it inevitably causes damage to the body's coagulation system, leading to the incidence of postoperative thromboembolism; thus, detection of some markers to diagnose and prevent thromboembolism is required (16). D-D is a degradation product of cross-linked fibrin. The content of D-D increases when blood is in a hypercoagulable state and fibrinolytic activity increases (17). GMP-140 is a particle surface membrane protein that is dependent on platelet activation and is the most sensitive indicator of platelet activation (18). TAT is the product of the link of serine residue of thrombin to the arginine residue of AT-III through ester bond. TAT can reflect the coagulation condition in vivo (19). Results of the present study showed that the levels of D-D, GMP-140 and TAT increased at 1 and 3 days after treatment, and decreased 7 days after treatment to reach normal level. This is because the thermal effect of radiofrequency ablation can increase local temperature and activate platelets. Local myocardial necrosis can cause the release of coagulation factors to accelerate platelet activation. The presence of radiofrequency ablation can cause damage to endothelium, leading to platelet aggregation and adhesion, and thus activate the body's coagulation system. Thus, levels of D-D, GMP-140 and TAT rapidly increase (20).

Atrioventricular node can be divided into fast and slow functional pathways. Radiofrequency ablation mainly targets the slow pathway to improve the success rate of treatment and reduce recurrence rate (3 to 5\%) (21). In the present study, postoperative recurrence was observed in 15 of 312 cases. Logistic regression analysis showed that residual slow pathway $(\mathrm{OR}=6.718, \mathrm{P}=0.005)$ and inaccurate targeting $(\mathrm{OR}=2.815$, $\mathrm{P}=0.007)$ were two independent risk factors for postoperative recurrence $(\mathrm{P}<0.05)$. After radiofrequency ablation, residual slow pathway can cause shortening of the refractory period, leading to AVNRT (22). The mapping of bypass pathway is the key for the success of radiofrequency ablation. Without accurate targeting, bypass pathway can be damaged by radiofrequency ablation, so necrosis will happen and recurrence rate will increase (23).

In summary, the efficacy of radiofrequency ablation in the treatment of pediatric SVT is clear. Although this treatment can damage cardiac vagal nerve; thus, the heart rate after ablation during the course of the tilt table test will increase, but it will return to normal after a week. Residual slow pathway and inaccurate targeting were two independent risk factors for postoperative recurrence.

\section{Acknowledgements}

Not applicable.

\section{Funding}

No funding was received.

\section{Availability of data and materials}

The datasets used and/or analyzed during the current study are available from the corresponding author on reasonable request. 


\section{Authors' contributions}

CL wrote the manuscript and helped with preoperative preparation. LJ and ZW performed radiofrequency ablation. LN contributed to tilt table test. XA analyzed and interpreted ELISA. All authors read and approved the final manuscript.

\section{Ethics approval and consent to participate}

The study was approved by the Ethics Committee of the Affiliated Children's Hospital of Xuzhou Medical University (Xuzhou, China) and informed consents were signed by the patients and/or guardians.

\section{Consent for publication}

Not applicable.

\section{Competing interests}

The authors declare that they have no competing interests.

\section{References}

1. Bánhidy F, Ács N, Puhó EH and Czeizel AE: Paroxysmal supraventricular tachycardia in pregnant women and birth outcomes of their children: A population-based study. Am J Med Genet A 167A: 1779-1786, 2015.

2. Brembilla-Perrot B, Olivier A, Villemin T, Manenti V, Vincent J, Moulin-Zinsch A, Lethor JP, Tisserant A, Marçon F and Jean Marc S: Follow-up of children or teenagers with paroxysmal supraventricular tachycardia but without preexcitation syndrome. Arch Cardiovasc Dis 110: 599-606, 2017.

3. Chou CP, Lin IC and Kuo KC: A male infant had subdural effusion and paroxysmal supraventricular tachycardia during the febrile episode of Kawasaki disease: A case report and literature review. BMC Pediatr 16: 71, 2016.

4. Bends R, Brössner A, Felberbaum R and Römer T: Myoma in statu nascendi after transcervical radiofrequency ablation of a transmural uterine leiomyoma. Gynakologische Endokrinologie 14: 291-294, 2016.

5. Kuck KH, Brugada J, Fürnkranz A, Metzner A, Ouyang F, Chun KR, Elvan A, Arentz T, Bestehorn K, Pocock SJ, et al: FIRE AND ICE Investigators: Cryoballoon or radiofrequency ablation for paroxysmal atrial fibrillation. N Engl J Med 374: 2235-2245, 2016

6. Zhao QX, Zhao YM, Mao L, Shen DL and Zhao XY: Atrial fibrillation prevalence and atrial vulnerability analysis in paroxysmal supraventricular tachycardia patients after radiofrequency ablation. Eur Rev Med Pharmacol Sci 21: 584-589, 2017.

7. Al-Zaiti SS and Magdic KS: Paroxysmal supraventricular tachycardia: Pathophysiology, diagnosis, and management. Crit Care Nurs Clin North Am 28: 309-316, 2016.

8. Spanò F, Cereda A, Moreo A, Bonacina E, Peritore A, Roghi A, Giannattasio C and Pedrotti P: Paroxysmal supraventricular tachycardia as first manifestation of right atrial hemangioma during endovascular treatment of intracranial arteriovenous fistulas. Oncotarget 6: 14060-14064, 2015.

9. Kruchina T, Gordeev O, Pushkareva I and Novik G: P1795 Presyncope and syncope events in pediatric patients with paroxysmal supraventricular tachycardia. Europace 19: 397, 2017.
10. Shaker H, Jahanian F, Fathi M and Zare M: Oral verapamil in paroxysmal supraventricular tachycardia recurrence control: A randomized clinical trial. Ther Adv Cardiovasc Dis 9: 4-9, 2015.

11. Sung JY, Baek JH, Jung SL, Kim JH, Kim KS, Lee D, Kim WB and Na DG: Radiofrequency ablation for autonomously functioning thyroid nodules: A multicenter study. Thyroid 25: 112-117, 2015.

12. Han J, Xu J and He Y: Anterior mitral leaflet perforation: A rare complication of radiofrequency ablation for paroxysmal supraventricular tachycardia. Clin Case Rep 5: 1414-1415, 2017.

13. Qian LY, Zou H, Che XD, Wang LH, Cen XX, Xu Q and Qu BM: Comparison of radiofrequency catheter ablation for paroxysmal supraventricular tachycardia guided by three dimensional navigation with X-ray. Zhonghua Yi Xue Za Zhi 96: 2821-2824, 2016 (In Chinese).

14. Seizer P, Bucher V, Frische C, Heinzmann D, Gramlich M, Müller I, Henning A, Hofbeck M, Kerst G, Gawaz M and Schreieck J: Efficacy and safety of zero-fluoroscopy ablation for supraventricular tachycardias. Use of optional contact force measurement for zero-fluoroscopy ablation in a clinical routine setting. Herz 41: 241-245, 2016.

15. Yu M, Yi K, Zhou L and Tan X: Pregnancy increases heart rates during paroxysmal supraventricular tachycardia. Can J Cardiol 31: 820.e5, 2015.

16. Menéndez JJ, Verdú C, Calderón B, Gómez-Zamora A, Schüffelmann C, de la Cruz JJ and de la Oliva P: Incidence and risk factors of superficial and deep vein thrombosis associated with peripherally inserted central catheters in children. J Thromb Haemost 14: 2158-2168, 2016

17. Man YN, Wang YN, Hao J, Liu X, Liu C, Zhu C and Wu XZ: Pretreatment plasma D-dimer, fibrinogen, and platelet levels significantly impact prognosis in patients with epithelial ovarian cancer independently of venous thromboembolism. Int J Gynecol Cancer 25: 24-32, 2015.

18. Cenni E, Granchi D, Verri E, Cavedagna D, Gamberini S, Falsone G and Pizzoferrato A: CD62, thromboxane B2, and beta-thromboglobulin: A comparison between different markers of platelet activation after contact with biomaterials. J Biomed Mater Res 36: 289-294, 1997.

19. Csuka D, Veszeli N, Imreh É, Zotter Z, Skopál J, Prohászka Z, Varga L and Farkas H: Comprehensive study into the activation of the plasma enzyme systems during attacks of hereditary angioedema due to C1-inhibitor deficiency. Orphanet J Rare Dis 10: 132, 2015.

20. Izumi N, Asahina Y, Noguchi O, Uchihara M, Kanazawa N, Itakura J, Himeno Y, Miyake S, Sakai T and Enomoto N: Risk factors for distant recurrence of hepatocellular carcinoma in the liver after complete coagulation by microwave or radiofrequency ablation. Cancer 91: 949-956, 2001.

21. Kovalev A, Filatov A, Bockeria O and Bockeria L: P317 The usefulness of radiofrequency ablation of atrial tachycardias in young patients with significant paroxysmal atrial fibrillation. Europace 19: 51, 2017.

22. Reddy CD, Silka MJ and Bar-Cohen Y: A comparison of AV nodal reentrant tachycardia in young children and adolescents: Electrophysiology, ablation, and outcomes. Pacing Clin Electrophysiol 38: 1325-1332, 2015.

23. Cooper RM, Shahzad A, Hasleton J, Digiovanni J, Hall MC, Todd DM, Modi S and Stables RH: Radiofrequency ablation of the interventricular septum to treat outflow tract gradients in hypertrophic obstructive cardiomyopathy: A novel use of CARTOSound ${ }^{\circledR}$ technology to guide ablation. Europace 18: 113-120, 2016.

This work is licensed under a Creative Commons Attribution-NonCommercial-NoDerivatives 4.0 International (CC BY-NC-ND 4.0) License. 